\title{
LA UNIVERSIDAD NACIONAL DEL COMAHUE (UNCo) Y EL DESARROLLO DE GRUPOS ACADÉMICOS. EL CASO DEL LABORATORIO ECOTONO EN SU ETAPA FUNDACIONAL
}

\author{
María de los Angeles Colodro (UNCOMAHUE)*
}

\section{Resumen}

Esta presentación se deriva de la investigación "Procesos y Dinámicas de formación y socialización en la Universidad Nacional del Comahue (UNCo): el caso de los grupos académicos de excelencia". (Directora de Proyecto local: Mag Marcela ICKOWICZ; Asesora: Profesora Titular Consulta Universidad de Buenos Aires Lic. Lidia M FERNÁNDEZ (Facultad de Ciencias de la Educación, Universidad Nacional del Comahue C-091). Intenta focalizar en el análisis de un grupo académico de la UNCo, el ECOTONO, con el propósito de profundizar en su etapa fundacional. Según Ulloa (1969) en dicha etapa se conforman los "núcleos pre institucionales" constituidos por grupos de personas que se unen alrededor de un proyecto común y que pueden llegar a funcionar, más adelante, como los fundadores y/o líderes académicos. En este tiempo pueden darse ya conflictos y diferencias, que pueden resurgir más adelante. En el caso analizado, focalizaremos en la fundación del laboratorio ECOTONO.

\section{Palabras Clave}

Grupos - Fundadores - Trayectorias académicas - Transmisión generacional.

\begin{abstract}
This presentation is derived from research "Dynamic Processes and training and socialization UNCo: the case of groups of academic excellence." (Local Project Manager: Mag Marcela Ickowicz, Advisor: Professor Lidia See UBA Mr. M FERNÁNDEZ (FACE UNCo C-091). Try to focus on the analysis of an academic group of UNCo, ecotone, with the aim of deepen their foundation stage. According to Ulloa (1969) in that stage up the "institutional pre-core" consisting of groups of people coming together
\end{abstract}

Licenciada en Ciencias de la Educación. Universidad de Buenos Aires. Doctoranda en Educación. Facultad de Ciencias de la Educación de la Universidad Nacional del Comahue. 
around a common project that might work, later, as the founders and / or academic leaders. At this time there may be conflicts and differences which may emerge later. In the present case, we will focus on the foundation of the study group ecotone.

\section{Key Words}

Groups - Founders - Academic trajectories - Generational transmission.

\section{El interés por estudiar los grupos académicos y el propósito general de este estudio.}

La historia de nuestro país y sus universidades está atravesada por quiebres y fracturas institucionales de distinto tipo que han producido cortes abruptos en el trayecto de los investigadores y los grupos académicos. Tanto en lo que se refiere a su desarrollo científico, como a los procesos de formación propios y de sus discípulos. No obstante existen grupos académicos que a pesar de condiciones francamente adversas han logrado sostener en el tiempo su producción y calidad.

Interesa conocer y analizar los rasgos de identidad y los modos de funcionamiento que caracterizan a estos grupos, en particular los grupos académicos de excelencia de la Universidad Nacional del Comahue (UNCo). Se procura comprender las condiciones y dinámicas institucionales relacionadas con el "sostén en producción" a través de tiempos que pueden caracterizarse como críticos, ya sea por inestabilidad del ambiente social e institucional externo o interno. Se presta especial atención a los rasgos singulares que puede presentar esa dinámica por tratarse de grupos de una Universidad regional y relativamente joven dentro del sistema universitario nacional, como es al Universidad Nacional del Comahue.

Se tiene especial interés en comprender la relación entre los rasgos que caracterizan a estos grupos y su capacidad para sostener la producción académica a pesar del impacto de situaciones críticas sociales e institucionales y dentro de un proceso que puede considerarse, para la UNCO, de incipiente institucionalización de la investigación.

\section{Breve noticia sobre el carácter de la investigación, su diseño general y su encuadre metodológico}

Se trata de una investigación de carácter exploratorio que procura definir con mayor precisión el problema y el objeto de estudio así como afinar conceptualizaciones que permitan dar cuenta con mayor precisión de su complejidad. Los grupos académicos, los académicos y la excelencia están siendo objeto de interés y estudio desde varias perspectivas y una de las intensiones de los 
análisis comparativos con los equipos de México y España tiene que ver con avanzar en esos propósitos.

El diseño de indagación se encuadra en los estudios intensivos de caso y se enmarca en la línea de las investigaciones institucionales cualitativas. Se toma como caso un grupo académico y se define como referente empírico de la designación grupo en primer orden (grupo-familia o grupo constelación) al conjunto de personas que a partir de uno/a que tiene reconocimiento como líder académico reputado, conforman lo que estamos llamando provisoriamente su árbol genealógico científico, familia académica o constelación académica tal como el o ella puede reconstruirlo (y lo reconoce).

Se entiende que este líder sostiene posiciones, perspectivas, modos de definir la ciencia y el científico etc. que ha procurado desarrollar y trasmitir y que ellas pueden ser consideradas partes de una cultura o un estilo que se vincula a la identidad de los definidos como integrantes de un tal grupo.

Se indaga en la reconstrucción del grupo-árbol/familia/constelación: figuras históricas del campo disciplinar mencionadas por el líder científico como referentes de las posiciones que se sostienen y que definen una identidad, los maestros del líder reputado, los maestros que ellos reconocen o reconocían , los pares, los discípulos y los discípulos de estos.

A partir de la esta reconstrucción se seleccionan creaciones organizacionales (institutos, Laboratorios, centros etc.) del académico fundador y de los investigadores que lo siguen generacionalmente (y están ubicados en el grupo -árbol/ familia/constelación, para estudiar en ellas el impacto de la trasmisión de culturas institucionales en lo que hace específicamente tanto a los temas y modos de producción científica y de formación como a las modalidades de sostén y desarrollo de las organizaciones que albergan esos procesos.

En la práctica y por su encuadre el estudio procura avanzar por etapas y para cada una prevé una secuencia que contempla: a) recolección de la información; b) primer análisis del material obtenido; c) devolución y validación y d) reajuste de instrumentos y de la etapa subsiguiente según avances validados por los integrantes del grupo caso. El cumplimiento de estos ciclos depende obviamente de las posibilidades reales que encuentre el equipo de investigación.

En la reconstrucción del grupo -"familia o constelación académica" La obtención de información se realiza en fuentes documentales y testimoniales a través de historias de vida e historias de vida académicas y se utilizan como herramientas analíticas los árboles genealógicos, las líneas históricas con atención a diferentes temporalidades, el análisis de contenido y la reconstrucción de situaciones.

En el estudio de las creaciones organizacionales, grupo-organización, se ha utilizado como herramienta de base el Estado de situación institucional (ESI), dispositivo que utiliza perspectivas histórico situacionales y procura una caracterización del estilo y la cultura institucionales. 
Los Estados de situación institucional (Fernández, L, 1984) se basan en el trabajo con fuentes documentales, testimoniales y en la observación en campo, utilizando como instrumentos en el caso de las testimoniales, cuestionarios, entrevistas abiertas en profundidad a informantes calificados e historias de vida, así como talleres de historización institucional y relevamientos fotográficos.

En general a partir de un diseño matriz la indagación se modifica para adaptarse a las características y posibilidades del grupo-organización en análisis.

\section{Ubicación del caso: Dr. E. Rapoport y el ECOTONO y los investigadores en la UNCo}

La selección del Dr. E. Rapoport y el Laboratorio ECOTONO se hace sobre la base de la consulta a los Secretarios Académicos de la UNCO y las autoridades del CRUB. En el análisis de la vida y producción del Dr. Rapoport se obtuvo su colaboración para reconstruir su trayectoria familiar y de vida así como su trayectoria académica.

Los Anexos I a IV muestran el avance en algunos de los materiales producidos por estos análisis. En ellos se está prestando especial atención al modo en que los movimientos geográficos e institucionales se articulan tanto con los acontecimientos socio políticos como con los que parecen rasgos de su estilo personal. Se estima plausible encontrar relaciones entre esas articulaciones y los rasgos que este líder académico imprime a la gestión institucional del Laboratorio.

La Universidad Nacional del Comahue se crea en el año 1972 en el marco de una política de expansión del sistema universitario argentino que se lleva a cabo fines de los ' 60 y principios de los ' 70 un plan de reorganización del sistema universitario que finaliza con la creación de 12 universidades. La UNCo tiene una Universidad con una estructura académica particular (Ver gráficos en los anexos).

La reconstrucción de la historia de la investigación y los investigadores en la UNCo permite advertir la incidencia de un conjunto de condiciones entre las que parecen resultar de especial significación.

a) la creación y los primeros años (1971-1974) en los que el debate pareciera girar en torno a la concreción de un modelo humboltiano vs un modelo profesionalista al que concurre la discusión acerca de universidad regional/ universidad nacional.

b) los primeros años de esta universidad están signados por el momento crítico propio de la creación pero fuertemente enlazados a la crisis que vive el país en esos años la última dictadura militar después (1976-1983) que interrumpe el proceso de creación y debate del proyecto UNCo.

c) los primeros años de recuperación de la vida democrática y académica (1984-1993). En el caso que nos ocupa serán los años en que se intenta 
instalar la investigación, como actividad o función propia de la universidad estimulada a partir de 1984, e institucionalizándose en convenios y normativas específicas desde 1986.

d) la introducción de políticas centralizadas desde la Secretaría de Políticas Universitarias (se crea en 1993) de control sobre la producción basadas en la asignación de retribuciones y subsidios frente a la aceptación de criterios uniformes para todas las universidades nacionales.

En esta presentación se focalizará en la tercera etapa (1984-1993) en la que se origina el grupo original ECOTONO con el fin de vincular las trayectorias académicas de los fundadores y comprender más a cerca del origen de esa organización.

Las fuentes que utilizamos para reconstruir esta etapa son: testimonios del fundador (ER) recabados en entrevistas tomadas en febrero de 2008, abril de 2009, octubre de 2009; reconstrucción de su trayectoria académica y científica; análisis de documentos publicados en Internet y de su pagina web; del libro "Aventuras y desventuras de un biólogo latinoamericano"; entrevista a ER publicada en la Revista Ciencia Hoy y entrevistas a los demás miembros fundadores.

Intentaremos aproximarnos a relacionar el estilo que marca la vida de ER: el cambio de lugar, de temas de investigación y el modo particular de gestionar la organización ECOTONO. Analizar la trasmisión que se da de determinados valores de ER en la línea de sucesión.

En este trabajo asumimos el carácter arbitrario y subjetivo de la memoria, rescatamos que sin memoria no hay historia posible. Asimismo, las memorias, en su expresión de testimonios de la historia individual y grupal, ponen en juego, según no solo la memoria sino también la reflexión sobre uno mismo. "Los testimonios pasan a ser considerados como 'verdaderos' instrumentos de reconstrucción de la identidad y no solamente relatos factuales, limitados a una función informativa" (Pollack, 2006, p. 13).

El cuerpo conceptual de referencia para esta presentación se nutre del aporte de los enfoques disciplinares de la Psicología institucional de raíz psicoanalítica, fundamentalmente los aportes de (Kaës Rene, 1989) y (Winnicott Donald, 1971), la sociología clínica de las instituciones en los aportes de (Enriquez Eugene, 1989), el socio psicoanálisis (Mendel Gerard, 1970), los estudios realizados en la psico dinámica del trabajo, en particular los trabajos de (Chistophe Dejours, 1992) y la teorización resultante de las investigaciones realizadas en nuestro país acerca de las instituciones educativas, en particular los estudios realizados por Fernández Lidia, 1983 en adelante.

\section{EI ECOTONO y sus fundadores. Dr. Eduardo Rapoport (ER)}

A los fines de esta presentación sólo incorporaremos la reconstrucción de los movimientos migratorios de este científico a partir de la historia de vida 
académica investigativa de Eduardo Rapoport para poder focalizar en la etapa fundacional del ECOTONO, ya que él es su principal referente. (Ver anexo). Uno de los antecedentes más importantes para entender su trabajo en ECOTONO es cómo arriba ER a Bariloche y luego, la labor desplegada en la Fundación Bariloche.

Intentaremos dar cuenta de algunos rasgos que para los sujetos adquiere el período fundacional de ECOTONO. Por el hecho mismo de haber compartido un conjunto de fenómenos sociales, culturales políticos e institucionales, los sujetos han construido ciertas disposiciones compartidas particularmente en cuanto a su participación en la historia institucional.

Si bien ECOTONO se crea en 1989, la fecha fundacional establece una marca en la temporalidad y señala un antes y un después. Para nosotros, el tiempo que le antecede se define como período pre fundacional Fernández (2006), y se vincula con la estada de ER en la Fundación Bariloche. Es un tiempo, como lo señala Ulloa (1969) en que se conforman los "núcleos pre institucionales". Esta es una de las razones de la relevancia del período pre fundacional.

- 1971 Y 1978 a la investigación científica en la Fundación Bariloche (ETAPA PRE FUNDACIONAL)

“... me llegó una carta de la Fundación Bariloche, una organización privada, pero de bien público, formada en buena parte por ex docentes de la Universidad de Buenos Aires que habían renunciado después de la tristemente célebre "Noche de los Bastones Largos", durante el golpe militar de Onganía. En ella me anunciaban que estaban en campaña de recuperar científicos que habían emigrado del país y me invitaban a regresar". (Libro aventuras y desventuras de un biólogo Latinoamericano: cap. 14, p. 14)

- la vida cotidiana, las condiciones de trabajo...

"EDORA: ¿Qué es lo que hacía la Fundación Bariloche en ese momento?"

EDOR: "Tenía varios departamentos, éramos unas 230 personas. Dto de Biología y Química..., Dto de Sociología, el Dto de Música, llegaban los becarios a estudiar, tenían una computadora, hoy mi computadora es mil veces más pequeña. Cuando entré era Recursos Naturales y Energía. (...)Era una maravilla, nunca volví a trabajar tan bien..., con tanta libertad..., sin burocracias. Las discusiones, las tremendas discusiones que se armaban five o clock..., nos reuníamos y era maravilloso estaban Amílcar Herrera, González Bonorino, Arístides Romero (el que después fue el rector de la Universidad del Comahue), muy generador, muy removedor de ideas, muy lindo (...) Gracias a la tranquilidad, el insuperable ambiente de 
trabajo y la calidad humana que encontré en la Fundación Bariloche". (Entrevista febrero 2008)

Podríamos pensar que en la etapa pre fundacional, esto es mientras ER estaba en la Fundación Bariloche ciertos rasgos de la modalidad de trabajo resultaron atractivos: la libertad, la ausencia de burocracia, la tranquilidad, la calidad humana, la formación de becarios.

- la curiosidad del investigador

"...una vez me hice una pregunta que fue para mí importante, crucial, que a uno se le ocurre una idea, esas cosas lindas, ¿cómo serán las formas de las áreas geográficas de las especies: ¿circulares, serán alargadas, serán ameboidales?, ¿cómo son las áreas por Km. cuadrados? Después, un continente, ¿cómo lo ocupan las especies? Cómo es si miráramos el continente desde el satélite, un continente entero, ¿cómo se enganchan y se superponen las áreas de las especies?" (Entrevista abril 2009).

- y una importante cuota de audacia

"Me pareció fascinante el tema, y ahí cambié, dejé colémbolos y toda la taxonomía..., abandone totalmente, quemé las naves y me fui para otro lado y encontré que hay una distribución muy inequitativa de espacio, hay muchísimas especies pobres, muertas de hambre, con la soga al cuello y especies ricas en kilómetros cuadrados y escasísimas millonarias..., lo llamé areografía, el estudio de las áreas, no aero, sino areografía" (Entrevista abril 2009).

El tiempo que le antecede a la fecha fundacional, en nuestro caso en 1989 se crea ECOTONO, se define como el período pre fundacional. Para los teóricos de las instituciones este período e central para entender la historia de las instituciones. En dicho tiempo se elabora el proyecto de la nueva institución. En este tiempo conflictos, diferencias, negados en su momento por las necesidades de impulsar los nuevos proyectos, pero que podrán resurgir más adelante. El tema del espacio es uno de los problemas pre fundacionales que también se reiterarán a lo largo de la vida de ECOTONO.

En el Golpe militar del ' 76 de 230 personas que estaban trabajando en la Fundación Bariloche, quedan 20. ER se queda sin trabajo. En 1976-77 se queda en Bariloche, hace artesanías, trabaja de albañil, hace instalaciones eléctricas. En 1977/'78 Recibe una invitación de Gonzalo Halffter, director del Museo de Historia Natural y del Instituto de Ecología y decide irse a México, D.F. (Distrito Federal). Trabaja en ecología urbana y de las especies invasoras.

"Yo no quería irme de Bariloche, así que aguanté durante un año haciendo artesanías y trabajando en instalaciones eléctricas. Aprendí a picar paredes y logré que la cuchara de albañil y el cemento obede- 
cieran las instrucciones de mi cerebro. Al final acepté una invitación del Instituto de Ecología de la Ciudad de México, donde trabajé especialmente en el tema de la contaminación por especies en regiones urbanas, algo con connotaciones y proyecciones sociales y psicosociales muy interesantes. México es una ciudad terrible, la antitesis de Bariloche. No sólo es gigantesca (vive el equivalente a la mitad de la población argentina) sino también súper contaminada". (Libro Aventuras y desventuras de un biólogo Latinoamericano: cap 15).

La dictadura, la escasa valoración y fomento a las actividades investigativas y las miserables condiciones de trabajo obligaron a muchos científicos a exiliarse del país. En este contexto ER viaja a México (ver gráfico)

La última experiencia autoritaria vivida en Argentina ha dejado un daño social y psíquico irreversible. El castigo brutal con que le terrorismo de Estado penó no sólo la acción sino el solo pensamiento y deseo de cambio social està vívidamente presente- si no en la memoria- sí en la reacción a todo acontecimiento que rompa con la pasividad frente al sufrimiento institucional y social (Fernández, 1996, p. 203).

\section{4: II Regreso: CRUB. ECOTONO. ETAPA FUNDACIONAL}

En su esfuerzo por dar origen, el grupo pre fundador y sus primeros adherentes (el grupo fundador) deben transitar tres caminos- según Fernández 1996-: a) el de la ruptura con el pasado y el enlace de la acción con el futuro; b) el de la fijación de puntos de apoyo y seguridad que garanticen el tiempo de concreción y c) el de la efectiva fundación y puesta en marcha.

En 1984 ER vuelve a Bariloche, durante un breve tiempo está sin trabajo hasta que lo llama el rector normalizador de la UNCo, para ingresar al Centro Regional Universitario Bariloche (CRUB). El grupo de Ecología con el nombre de ECOTONO, dirigido por Eduardo Rapoport pasaría a formar parte en 1989 de la Universidad Nacional del Comahue, manteniendo y acrecentando su prestigio a nivel internacional. El Departamento de Matemática y el de Transferencia, en cambio, se desintegraron igual que los grupos de Geología, Hidrología y Ecología del Departamento de Recursos Naturales y Energía.

"Pasadas cuatro semanas desde nuestro regreso, el triunfo de Raúl Alfonsín -que ya se preveía - confirmó el deseo de la gente de abandonar la locura y retornar a la vida democrática. Para ese entonces ardíamos en deseos de volver a Bariloche a ver a nuestros hijos, nietos, amigos... y casa que aún no conocíamos" (Libro Aventuras y desventuras de un biólogo Latinoamericano: cap 14).

El espacio y sus dificultades: 
"Hasta que un día, me llamó por teléfono Arístides Romero (rector de la UNCo), un geólogo con quien habíamos trabajado en la Fundación Bariloche. "Edy, te hablo desde Neuquén. Acabo de asumir el cargo de rector de la Universidad del Comahue. (...)! De manera tajante me anunció que desde el primero de febrero estaría contratado. (...) Así que cuando me presenté a inspeccionar el Centro Regional Universitario Bariloche, para ver qué posibilidades de espacio tenía para trabajar, nada me sorprendió, nada me tomó desprevenido. Se confirmaron mis peores expectativas y en lugar de deprimirme me embargó una profunda hilaridad. El edificio era del tamaño de una escuelita de provincia. Pretender un espacio para un laboratorio o gabinete era fútil. Tampoco había pared alguna donde colocar una estantería. Lo único disponible era compartir, con otro profesor, un pequeño escritorio durante medio día y usar uno de sus cajones para mis cosas." (Libro Aventuras y desventuras de un biólogo Latinoamericano: cap 14).

Cuando aludimos al rigen mítico reconocemos la existencia de acontecimientos y significados que van a permanecer a lo largo del tiempo en las subjetividades y formar parte de las tramas identitarias colectivas e individuales.

"Vista la situación y mi imposibilidad de trabajar, el nuevo decano propuso a la Fundación Bariloche subalquilar uno de los pequeños cuartos del hotel donde funcionaba es institución. B. vino a ayudarme ad-honorem por un par de años, luego se incorporó un ayudante alumno de la universidad y, por último, dos becarias. Más de dos personas no cabían en esa habitación. Las paredes fueron rellenadas hasta el techo de libros, carpetas, papeles, cartas, fotocopias y más de 25.000 separatas. También estaba atestado mi baño privado y el baño general, que logré invadir. El tipo de investigación que yo realizaba requería la constante provisión de información y despliegue de papeles, cuadros, listas de todo tipo y mapas. Si la información estaba a espaldas de B., ella tenía que abandonar su silla para que yo pudiera pasar. O había que correr el escritorio. El proceso se hacía en extremo lento y ya habían pasado casi tres años sin que yo pudiera terminar un solo tema de investigación. Las dos becarias debían trabajar en otros edificios públicos o en sus propias casas". (Libro Aventuras y desventuras de un biólogo Latinoamericano: cap 14).

El hacinamiento, la escasez de espacio, la carencia de recursos y la falta de condiciones materiales para desarrollar la tarea investigativa fueron la marca del origen. El proceso de formación y socialización de los primeros miembros de ECOTONO recibe la impronta de ER como pionero, que había luchado por instalar el laboratorio de biología. Se trata de un proyecto innovador, el grupo 
asume investiduras de carácter heroico a condición de no tener presupuesto. Según Fernández, L.: "En general el proyecto que este grupo formula sostiene una tesis que encierra un desafío enlazado con los componentes míticos y utópicos de la cultura: es posible lograr un "imposible" (...). Este modelo es al mismo tiempo la señalización del camino que se habrá de recorrer, y una propuesta de valores y significados con los que dar sentido al sacrificio y al esfuerzo que demandará el proyecto y con los que, de hecho, se protegerán el ingreso y la pertenencia" (1996, p. 202).

Pareciera que la propuesta de investigar casi sin recursos, no es para cualquiera, que ya desde los inicios se vislumbran que será difícil sostener este proyecto.

\begin{abstract}
"A todo esto yo ya había ingresado al CONICET y era miembro del Consejo Asesor. En una charla informal, el presidente del CONICET me preguntó cómo iba mi trabajo. Después de enterarse de mi situación, me preguntó: “¿Por qué no pides un subsidio para construir un laboratorio?" Al saber que ya lo había hecho, pero con respuesta negativa del CONICET respondió. "No puedo creerlo. Voy a averiguar qué ha ocurrido". Al tiempo recibí una carta del CONICET informándome que se me había otorgado un subsidio para la edificación de un laboratorio. Entre las cláusulas, el contrato estipulaba que los fondos debían ser depositados en australes en un banco, cosa que cumplí obedientemente. Pero el desastre que se desató durante la hiperinflación galopante puso en serios aprietos el proyecto. (...). Si hubiéramos podido guardar en dólares el subsidio habríamos podido decuplicar sus dimensiones". (Libro Aventuras y desventuras de un biólogo Latinoamericano)
\end{abstract}

La dificultad inicial de obtener subsidios se allana con la entrega del subsidios del CONICET para edificar el laboratorio; pero a poco de andar se presenta otro obstáculo: la híper inflación, con lo cual, nuevamente los recursos no alcanzan. El modo de resolución de los múltiples conflictos iniciales pareciera está signado por un guión utópico. Fernández, L expresa: "Haya elaborado su modelo fundacional sobre el guión mítico o el guión utópico, la fundación propone un camino heroico y las vicisitudes de esta propuesta signan los primeros tiempos del trayecto." (1996, p. 212)

Utilizaremos el esquema de Fernández, L (1996) para analizar la puesta en marcha. La misma exige la atención de puntos críticos en áreas cruciales:

Las personas: pareciera que el proyecto es convocante para los miembros: algunos viajan de Bs As a Bariloche para trabajar con ER, otros buscan la libertad, otros lo buscan a partir de leer su libro Aerogeografía,

"Entonces, yo no encontraba en La Plata la posibilidad de encontrar a alguien que me formara en mi posgrado, entonces hablé con 
uno de mis profesores y le pregunté sobre alguien que me pudiera formar, el es paleontólogo, nada que ver con la ecología pero lo conocía, es el padre de un muy amigo mío, y el me recomendó a Rapoport que estaba volviendo al país, estaba en la Fundación Bariloche, hacía poco que habían llegado, no me acuerdo, y me tomé el tren y lo vine a ver, en esa época había tren(...) Y, él me recibió en su oficina y hablamos, y después seguimos hablando por carta porque no había mail, no había nada". (Entrevista Est. Raf.)

"Si esa es una etapa que fue, como un ECOTONO que era el germen. Con la gente formándose y después se empezó a incorporar gente que estaba viniendo de afuera como T. y A., capaz que con otra perspectiva de las cosas, porque por ejemplo, la primera parte del ECOTONO, la primera época, no había laboratorio, habían dos computadoras. Todo el mundo escribía a mano, en papelitos, fichábamos las revistas, los trabajos en cartulinas, teníamos unas cajitas de madera, que mirá todavía hay alguna por ahí. Las había hecho Edi con cajones de manzana, nos hacia las cajas para poner las fichas. Mirá esta es la más rústica. Era una cosa así muy del papá o la gallina con los pollitos, esa era mi sensación con Edi. Yo nunca, no tengo el recuerdo así de Edi, dándome instrucciones así de trabajo, pero era así como cuidando que pudiéramos trabajar, pero con total libertad" (Entrev. M.T.C).

\section{- Las condiciones institucionales}

"Fundamentalmente el tema de los proyectos tiene que ver con la financiación, cuantas más personas son, menos plata va a haber para cada uno. Entonces es mejor tener grupos chicos, todos financiados, que tener un gran grupo con una financiación, con las financiaciones de la Universidad, vos sabrás, son bastantes pobres. Cuando hay, siempre hay unos manguitos. Yo soy gasolera, yo uso papel y tinta y algunos libros, fotocopias. Bueno, por ejemplo, mis compañeros de grupo salen al campo y están..., muchas cosas que son caras, las cosas de laboratorio. Bueno, desde que se inauguró esta ala, yo estoy acá, estoy en un grupo, ahora estoy dirigiéndolo yo al grupo, que trabajan en Ecología todos" (Entrev. M. T.C).

"El grupo ECOTONO tiene como varias etapas, una etapa de los viejos, tiene una etapa como de un grupo chiquito de personas, como por supuesto una familia chiquita. Los problemas que pueden surgir entre las personas y roces que se yo, pero lo normal en cualquier grupo que está confinado en $80 \mathrm{~m} 2$, que era cuando la parte del ECOTONO, cuando no se había hecho la ampliación". (Entrev. M. T.C) 
"Es un grupo que ha conseguido dinero, pero tampoco creo que sea lo más importante sinceramente, y ha sido muy generoso, muchas veces cuando ha tenido dinero lo aporta acá." (Entrevista Est. Raf.)

- Las relaciones con el medio institucional: pareciera que el sentido del humor les permitió lograr institucionalización. Reconocimiento y posteriormente, apoyo.

"A pesar de todas las restricciones presupuestarias, el Centro Regional Universitario y nuestro laboratorio, crecieron casi por milagro. EI CONICET nos apoyó con becas e incorporación de investigadores, y luego lo hizo con la misma universidad. Sin embargo, las mesas de trabajo las construimos nosotros, las sillas las trajimos de nuestras casas, lo mismo que las cortinas y estanterías. (...) Conseguí reunir un grupo de jóvenes investigadores brillantes y pujantes, proclives al trabajo en equipo. Lo que jamás conseguí fue que siguieran mis consejos para el buen funcionamiento del edificio". (ER; Libro Aventuras y desventuras de un biólogo Latinoamericano).

En las relaciones internas me parece que acá es el punto mayor logrado: lograr claridad en la definición de responsabilidades, logar satisfacción de las necesidades de pertenencia y acordar reglas de participación en las decisiones.

"Yo no creo que haya nadie que se sienta excluido de acá, porque es una cosa, es como muy hippie esto, no? Es una cosa muy comunitaria, entonces, no sé cómo será la sensación de todos no, pero en general, es una cosa de mucha camaradería, que se yo, cuando alguno termina su doctorado, en general, hay una fiesta fantástica. El año pasado hicimos una fiesta para la primavera, tenemos la comisión de asuntos divertidos del ECOTONO, de la cual formo parte. Comisión de Asuntos Divertidos, claro, el CADE". (Entrev. M.T.C)

"Después, yo creo que hay una cosa que es muy saludable, que es la búsqueda de espacio de camaradería. Se hacen en noviembre los cumpleaños de los escorpianos. No sé si vos viste que hay en la cocina una lista de los cumpleaños y hay un montón de gente de cáncer y un montón de gente de Escorpio, entonces, se hace los cumpleaños de los escorpianos, y es un lugar donde cada uno va con su familia, compartimos un asado, en un lugar lindo. Como que esa cosa de camaradería grupal, general. Yo no la he visto en otro lado.". (Entrev. M.T.C).

"Hemos puesto dinero de nuestros bolsillos, durante años. Esta computadora me la compré yo, con mi plata, con mi tarjeta de crédito. Como que esas cositas de funcionamiento, no teníamos, hasta el año pasado nos teníamos como pagar Internet, este año no, pero 
estas cosas. (...) Porque en realidad se podrían hacer muchas cosas, pero no hay donde hacerlas. Se podrían traer personas pero no hay donde traerlas, no? El recurso espacio es un limitante, pero no se si, o sea es una dificultad, pero no sé si produce una fractura en el grupo, yo nunca tuve, bah yo soy medio Heidi, nunca me entero de nada. Creo, yo no creo haber notado en la historia de ECOTONO un fraccionamiento del grupo, no? ¿Y qué cosas ayudan a que se consolide como grupo? Capaz que el hecho de que no haya un jefe, porque no sé, no sé cómo hacemos. Igualmente funciona y eso es lo maravilloso, porque es como una cosa muy anárquica". (Entrev. M.T.C)

"Y funcionamos bien, no? Que se yo, tenemos organizaciones, una vez al año tenemos una reunión de organización, y armamos como comisiones voluntarias de cosas, que se yo, hay una que tenemos una compra comunitaria anual, eh mensual de cosas de que se yo yerba, café. Son grupos de a 2 que se hace una lista larga de grupos de 2 y cuando te toca te toca. Juntas la plata, vas, haces las compras, pones las cosas en la alacena, cambias la lamparita si hay que cambiar, te comunicas con los de mantenimiento si hay algún problema. Esa es una comisión que rota, mes a mes. Después hay una comisión de la que mantiene la biblioteca, la hemeroteca, que es también un año entero, dos personas, que son las que reciben las publicaciones, las ponen. Pero es algo, que todos lo cuentan y comentan que es bárbaro que así sea, mas allá que no tenían personal administrativo, es como un valor, un valor, por eso, por eso la pregunta de cómo se instala, porque es algo valorado, reconocido, se sigue sosteniendo en el tiempo". (Entrev. M.T.C).

Pareciera que uno de los rasgos más salientes del grupo es la armonía que logran con respecto a las relaciones humanas. Si bien hay numerosos laboratorios y grupos de prestigio académico en el país, este grupo se destaca por la interacción que tienen entre sus integrantes y las fuertes relaciones de camaradería y cooperación. Así como también las formas de autogestión que se tuvieron desde los orígenes, la horizontalidad, la no existencia de jefes que dijeran qué hacer y la participación en las decisiones, ya sea de mantenimiento del espacio, como de las decisiones académicas. En las diversas entrevistas y cuestionarios realizados a los miembros de las diferentes generaciones, el acento se pone en el estilo que ER legó y eso pareciera que es lo que hoy los sigue sosteniendo en la forma de hacer ciencia.

- Las estrategias y técnicas de trabajo (tarea nuclear): la tarea central es la investigación y para esto el grupo tiene que lograra acceso y circulación de conocimientos; desarrollar tecnologías adecuadas e instalar dispositivos de control de calidad. 
"Rapoport con una generosidad increíble les dio lugar de trabajo a todos, les dio el ámbito físico a todos, pero fue también como geográfico, como decirte, ellos tampoco respondieron a él temáticamente, él les dio el amparo de firmarles como director, pero también ellos crearon sus líneas y trabajaron por su cuenta" (Entrev. DG).

"No son estos grupos estructurados, donde el becario tiene que entrar a las ocho, irse a las cuatro, rendirle cuentas a su director de todo lo que hace, que se yo..., mis becarios pueden hacer trabajos con otras personas y yo no estar, y me parece bien, es más, es lo que me gustarian que hagan..., porque fue lo que yo hice y es bueno eso y no quedarse solamente con la tesis". (Entrevista Est. Raf.)

Nuestra propuesta conjetural sobre la persistencia del grupo en producción a pesar de situaciones críticas se vincula con le modo en que aspectos de la cultura y el estilo institucional de ECOTONO caracterizados operan en situaciones cotidianas y parecen haber operado en momentos críticos posibilitando -según los relatos y reconstrucciones- el sostén de la producción científica del grupo y la organización creada.

Además pareciera que las características de la trayectoria del Dr. E. R, como líder académico fundador, su estilo y su posición referencial han sido parte del legado que los distintos miembros supieran capitalizar, especialmente la generación formada por ER que actualmente a su vez forma investigadores, a pesar de las circunstancias históricas y las condiciones materiales de la producción del Laboratorio.

\section{A modo de síntesis}

En el trabajo de escrutinio del período pre fundacional y fundacional se objetivan memorias en las cuales se hacen presentes acontecimientos, personajes, instituciones grupos, luchas, todos ellos de gran significación para los sujetos. Encontramos eslabones fuertes en la construcción identitaria ligados a la figura del fundador, ER en la que podríamos enumerar algunos rasgos que desde los inicios signaron con gran carga de ilusión el trabajo en ECOTONO: el ambiente de libertad, el respeto por los proyectos propios, la generosidad de ER en la firma de las tesis; el acompañamiento más emocional qué técnico; la disponibilidad de autogestionarse desde los recursos económicos y las condiciones de trabajo; el haber encontrado modo de organización comunitarios, sin jefes en los que se tomen las decisiones de modo democrático; el sentirse como "una familia" y estar pendientes desde los horarios para cortar el pasto hasta los turnos de limpieza del lugar de trabajo; el poder conseguir fuertes sumas a partir de ganar subsidios con el exterior; el lograr reconocimiento en la UNCo y en el CONICET; el construir un estilo de trabajo en donde el sentido del humor está en la base de las relaciones. 
Pareciera que con relación a los modos de investigar hay una cuestión de reserva, una necesidad de mantener el espacio con cierta protección. La universidad pública argentina parece que todavía lo permite a pesar de los nuevos criterios instalados en los '90.

Mirar estos grupos que producen conocimientos -para mayor información sobre la producción científica ver los CV en http://www.crub.uncoma.edu.ar/ ecotono/- a pesar de la adversidad de los acontecimientos históricos por los que tuvieron que atravesar y de las dificultades propias inherentes al sostenimiento de una modalidad disruptiva en lo que se refiere a los grupos académicos de excelencia, es admirable.

Un rasgo común de los investigadores de los grupos de estudio es que presentan 'modalidades progresivas de funcionamiento' Fernández (2000), con lo que resignifican permanentemente su trabajo y permanecen en pie a pesar de los avatares económicos y políticos de la universidad.

En la apuesta a un camino heroico, cada dificultad es vivida como un obstáculo; sin embargo, a pesar de las múltiples situaciones adversas que sufrió el grupo a lo largo de su historia, el grupo inicial y hoy sus discípulos o herederos, continúan transmitiendo un estilo de hacer ciencia que todavía parece sostener al grupo. ¿Continuarán produciendo conocimiento científico bajo esta modalidad instalada por ER o diseñarán otros modos de investigar?

Decíamos al comienzo que existen grupos académicos que a pesar de condiciones francamente adversas han logrado sostener en el tiempo su producción y calidad. Resulta interesante ver cómo es la función de la investigación en una universidad nacional que posee un Centro Regional en Bariloche, cómo se trasmite a otros de generación en generación este modo de producir conocimientos de alto valor académico y científico. Hacer visible el reconocimiento, la excelencia en la universidad pública de hoy, creemos es una tarea central.

\section{Notas Bibliográficas}

(1) Profesor emérito de la Universidad Nacional de Comahue, Argentina

(2) El Laboratorio Ecotono de la Universidad Nacional del Comahue contribuye desde 1989 a la generación de conocimiento científico en el vasto campo de la Ecología, en todas sus escalas e interfases con disciplinas tan diversas como Comportamiento Animal, Antropología, Sistemática, Evolución, Biogeografía, Paleoecología, Genética, y Fisiología Vegetal.

\section{Referencias Bibliográficas}

- $\quad$ Bauman, Z. (2005) Identidad, Buenos Aires, Losada

- Colodro, M. (2009) Rasgos en común que presentan los investigadores que son fundadores y a la vez actuales directores de Centros de estudios en la UNCo. Trabajo presentado en Primer Congreso Internacional de Pedagogía Universitaria. UBA, septiembre, Bs. As. 
- Debray, R. (1997) Transmitir, Ediciones Manantial.

- Didou, S. y Remedi, E. (2008) De la pasión a la profesión. Investigación científica y desarrollo en México. México, Casa Juan Pablo.

- $\quad$ Fernández, L. (2004) "Prólogo", en E. Remedi (coord.), La institución: un entrecruzamiento de textos, Mèxico, Plaza y Valdés.

(1996) "Crisis y dramática del cambio. Avances de investigación sobre proyectos de innovación educativa” en Butelman, I, Pensando las instituciones, Bs. As. Paidós.

- $\quad$ Grinberg, L. Y Grinberg R. (1993) Identidad y cambio, Buenos Aires, Paidós

- Hassoun, J. (1994) Los contrabandistas de la memoria, Buenos Aires, Ed. de la Flor

- Ickowicz, M. (2005) Modelos Formativos en la Universidad. En S. Barco. Universidad, Docentes y Prácticas: el caso de la UNComahue. Edit. Universidad Nacional del Comahue, 97-128.

- Informe de Avance Proyecto C- 075. (FACE, UNCo)

- $\quad$ Kaës, R (1989) La institución y las instituciones, Bs. As., Paidós.

- Kaës, R; Missenard, R y otros (1985.) Crisis, ruptura y superación, Buenos Aires, Edic. Cinco.

- Krotsch, P. (2001) Educación Superior y reformas comparadas. Bernal, Universidad Nacional de Quilmes.

- Landesmann, M., Hackman, H. y Parra, G. (2009) "Memorias e identidades institucionales. Fundadores y herederos en Psicología Iztacala". México, Juan Pablos Editor, Universidad autónoma de México.

- Landesmann, M. (2006) "Instituciones educativas. Instituyendo disciplinas e identidades", Mèxico. Juan Pablos.

- $\quad$ Libro 50 años del CONICET, 2006.

- $\quad$ Sartori Rugiu, A. (1996) Nostalgia del maestro artesano. Colección Problemas educativos de México. Serie Los clásicos. CESU, UNAM.

- Souto, M. (2000) Las formaciones grupales en la escuela. Bs. As., Paidós.

- Ulloa, F. (1969) "Psicología de las instituciones. Una aproximación psicoanalítica, Revista AAPA, Buenos Aires. Tomo XXVI,

Paidós.

(1995) Novela clínica psicoanalítica .Historial de una práctica. Bs. As. 


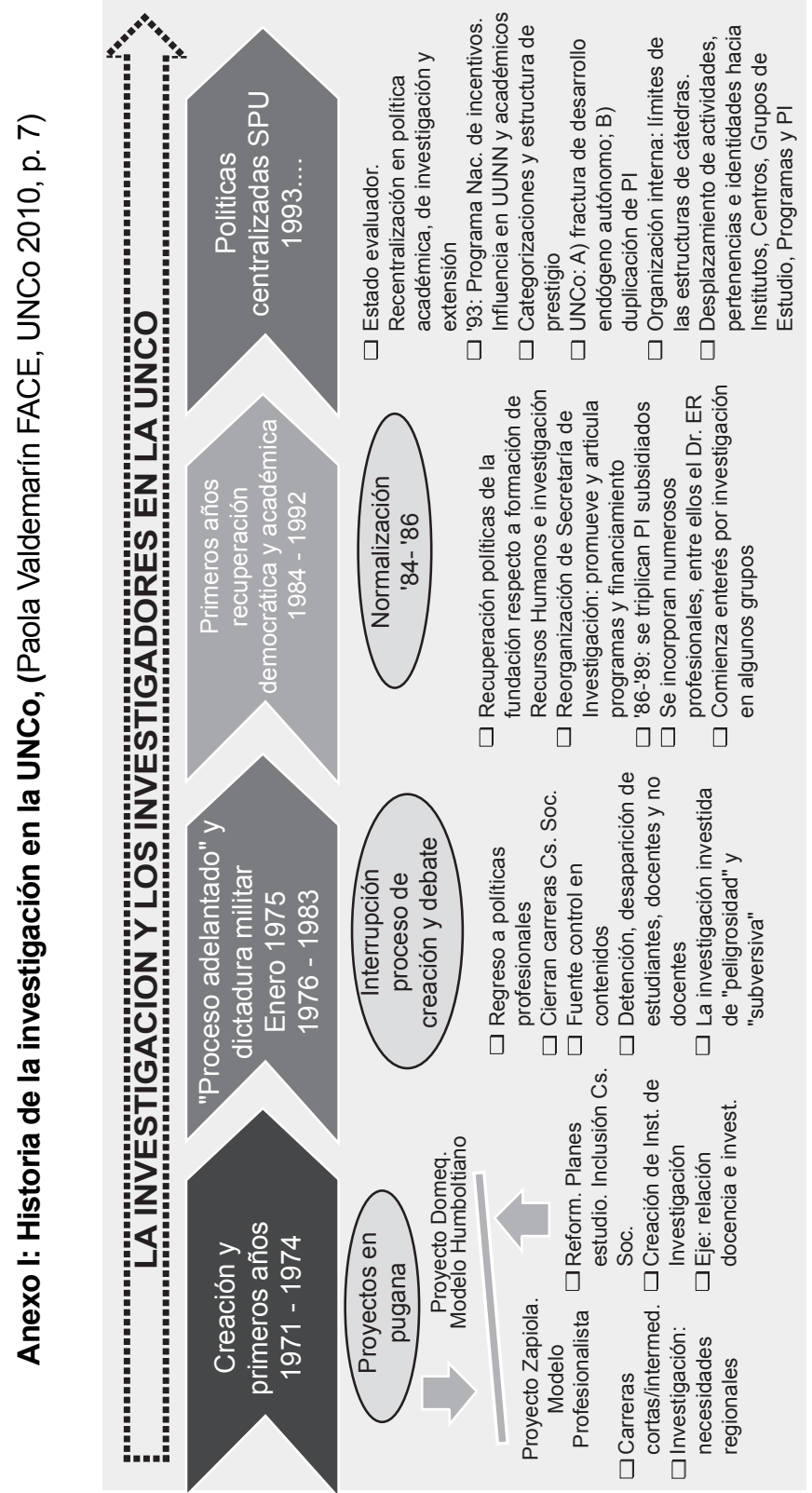




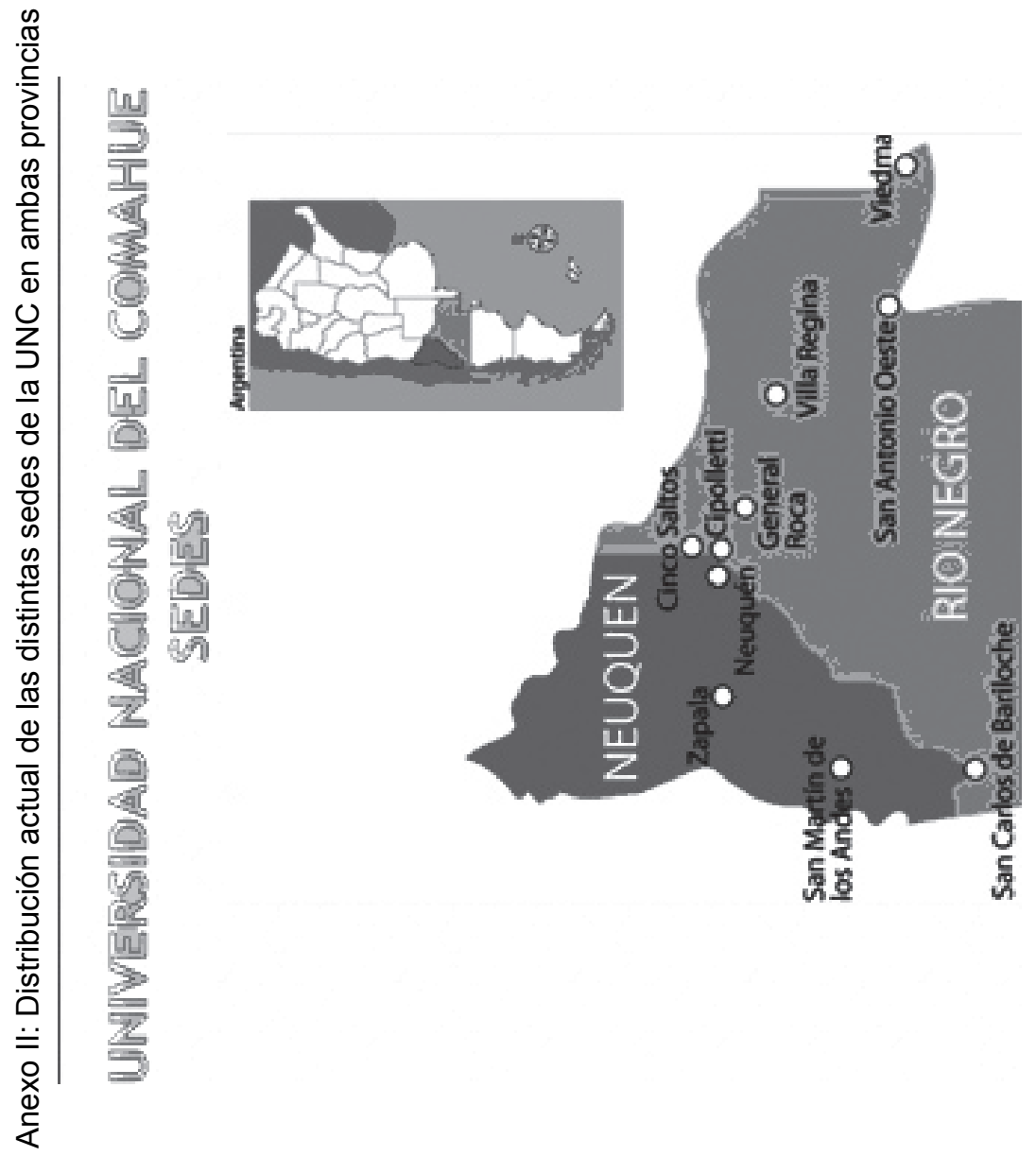




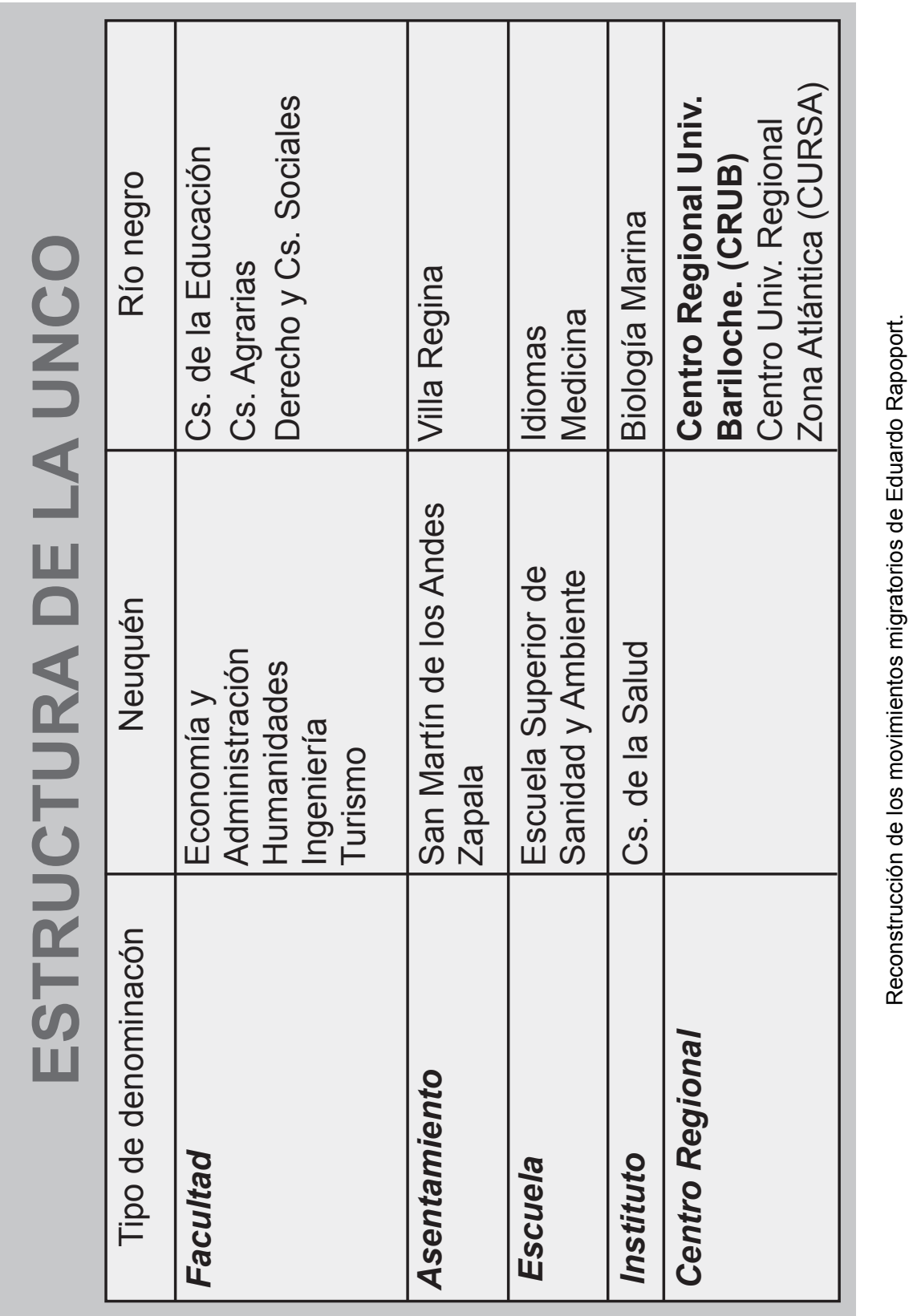




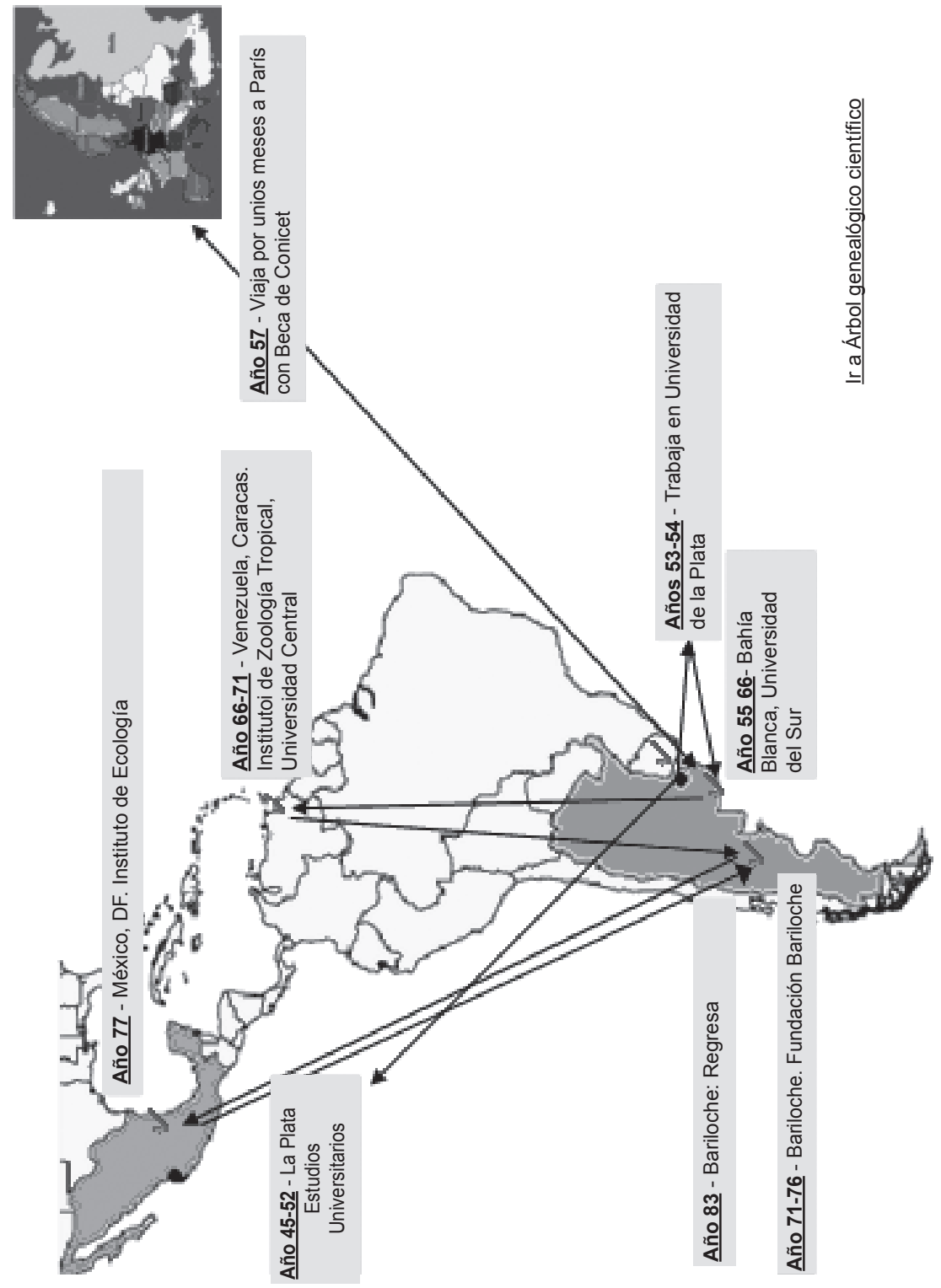

